Dijk, C.E. van, Innis, S.M. Growth-curve standards and the assessment of early excess weight/ gain in infancy. Pediatrics: 2009, 123(1), 102-108

\begin{tabular}{|l|l|}
\hline Postprint Version & 1.0 \\
\hline Journal website & $\underline{\text { http://pediatrics.aappublications.org/cgi/content/abstract/123/1/102 }}$ \\
\hline Pubmed link & $\underline{\text { http://www.ncbi.nlm.nih.gov/pubmed/19117867 }}$ \\
\hline DOI & $10.1542 /$ peds.2007-3382 \\
\hline
\end{tabular}

This is a NIVEL certified Post Print, more info at http://www.nivel.eu

\title{
Growth-Curve Standards and the Assessment of Early Excess Weight Gain in Infancy.
}

\author{
Christel Evellen VANDiJK, MSC AND SheILA Margaret InNis, PHD
}

Department of Pediatrics, Nutrition Research Program, Child and Family Research Institute, University of British Columbia, Vancouver, British Columbia, Canada

Address correspondence to Sheila M. Innis, PhD, Nutrition Research Program, 950 W 28th Ave, Vancouver, British Columbia, Canada V5Z 4H4. E-mail: sinnis@interchange.ubc.ca

The authors have indicated they have no financial relationships relevant to this article to disclose.

This trial has been registered at www.clinicaltrials.gov (identifier NCT00620672).

\begin{abstract}
OBJECTIVES. Increasing overweight and obesity are growing problems among children worldwide. Prevention requires an understanding of when excess weight gain begins and the determinants that place children at risk. The aim of our study was to illustrate how the growth curve used to assess growth influences the interpretation of weight gain and the age of onset of higher weight gains in infancy.

METHODS. This was a longitudinal study of Canadian infants from birth to 18 months of age. Infant feeding pattern was recorded monthly, and weight and length of 73 infants were measured at 8 different ages. Weight, length, weight for length, and BMI $z$ scores were compared with the Centers for Disease Control and Prevention 2000 growth curves and World Health Organization growth standard.
\end{abstract}

RESULTS. Comparison with the Centers for Disease Control and Prevention growth curves showed that Canadian infants grew similarly or slightly slower than their US counterparts. Using the World Health Organization growth standard, an increase in body weight occurred between 6 and 9 months of age, associated with a change from breastfeeding to formula feeding and introduction of solid foods. When compared with the World Health Organization standards, breastfed infants followed the standards, but formula-fed infants deviated with higher weight for age. When compared with the Centers for Disease Control and Prevention charts, breastfed infants showed an apparent decline in weight for age beginning at $\sim 6$ months.

CONCLUSIONS. The choice of growth curve is important to interpreting infant growth and identifying the onset of excess weight gain. Identification of the prevalence and age of onset of early excess weight gains among Canadian 
Dijk, C.E. van, Innis, S.M. Growth-curve standards and the assessment of early excess weight gain in infancy. Pediatrics: 2009, 123(1), 102-108

infants will be best achieved by using the World Health Organization growth standards.

\section{Abbreviations: CDC - Centers for Disease Control and Prevention $\bullet$ WHO-World Health Organization}

Obesity is becoming a worldwide epidemic that affects both adults and children. ${ }^{1-4}$ Recent estimates show that $>1$ in 4 Canadian children 2 to 17 years of age are overweight, and $8 \%$ are obese. ${ }^{3}$ Similar problems of increasing weight gain are also occurring among young children in Europe and the United States. ${ }^{5,6}$ Obesity is associated with an increased risk of multiple health problems, including diabetes mellitus type $2,{ }^{7-9}$ dyslipidemia, ${ }^{10}$ and elevated circulating inflammatory mediators. ${ }^{11,12}$ Recent studies have shown that problems of overweight extend to children under the age of 24 months, suggesting that both the accumulation of excess body weight and its associated comorbidities may start in infancy. ${ }^{7-9}$,

${ }^{13}$ More fundamentally, recent research has provided evidence of altered adipocyte morphology and inflammatory processes in the adipose tissue of obese children, similar to those in obese adults. ${ }^{14,15}$ Thus, adipose tissue responds to energy intakes in excess of requirements by storage of the excess energy as triglycerides, predominately in adipocytes. Resulting adipocyte hypertrophy, oxidative stress, and macrophage infiltration set the stage for a heightened inflammatory state in the adipose tissue. ${ }^{16}$ Evidence of adipocyte hypertrophy and degeneration and macrophage infiltration in adipose tissue of young overweight children has been published. ${ }^{14}$

Previous research has shown that overweight in infancy tracks to childhood obesity, which itself is associated with an increased risk of adult obesity. ${ }^{17-20}$ Thus, both the immediate effect on childhood health and implications for later adult health combine to emphasize the importance of prevention of excessive weight gain in infancy. However, prevention requires intervention initiatives that precede the time when the risk of onset is greatest, but the age of onset and dietary determinants of excess weight gain in infancy remain unclear. Although a sedentary lifestyle and overfeeding are central components of overweight in childhood, ${ }^{21,22}$ overfeeding may be a more important determinant of early excess weight gains in young infants. The choice of growth-curve standard to assess deviations in infant growth is problematic, because growth standards reflect the population on which they are based. ${ }^{23} \mathrm{We}$ sought to assess the importance of the growth standard in detecting changes in early infant growth by comparing growth data for healthy term gestation Canadian infants assessed in a prospective study with the Centers for Disease Control and Prevention (CDC) 2000 growth charts and the World Health Organization (WHO) growth standards.

\section{SUBJECTS AND METHODS \\ Study Design and Subjects}

Infants in the present study were participants in a prospective study designed to determine whether maternal $n-3$ fatty acid docosahexaenoic acid status in pregnancy influences neural development of term gestation infants. Pregnant women with no known complications and expected to deliver a single term infant were enrolled at 16 weeks of gestation with followup of all of the infants born at 37 to 42 weeks of gestation, with birth weight of 2500 to 4500 $\mathrm{g}$, and with no metabolic or physical problems until they reached 18 months of age. Inclusion criteria for pregnant women were registration to deliver a single infant at the British Columbia Women's Hospital, Vancouver, between April 2004 and April 2005, low-risk pregnancy, 20 to 40 years of age, and no known metabolic, physical, or communicable disease likely to impact either maternal or fetal health or fetal growth and development. The study was approved by the University of British Colombia Clinical Screening Committee for Research and Other Studies Involving Human Subjects and the British Columbia Children's and Women's Hospital Research Coordinating Committee. 
Dijk, C.E. van, Innis, S.M. Growth-curve standards and the assessment of early excess weight gain in infancy. Pediatrics: 2009, 123(1), 102-108

\section{Measurements of Infant Growth and Feeding}

Body weight and length were measured using standardized procedures for each infant at 1,2, $6,9,12,14$, and 18 months of age. Body weight was measured using an electronic pediatric scale to the nearest $0.01 \mathrm{~kg}$, and length was measured using a pediatric-length board with the infants in a recumbent position. ${ }^{24}$ Birth weight and length were recorded from hospital charts. Infant feeding was assessed in a face-to-face interview with the mother by a trained clinical research assistant when the infant reached 1, 2, 6, 9, 12,14, 16, and 18 months of age. At each interim month, information on infant feeding was collected by telephone. Changes in infant feeding and dates when new foods were introduced were continuously recorded by the parents throughout the study using an infant feeding diary. Specific questions were asked on the type of milk, including breast milk, formula, or both, the specific brand of formula, and the age of introduction. Questions were also asked about the timing of the introduction of solid foods and what they were, including infant cereals, vegetables, fruits, juices, red meats, poultry, fish, eggs, cheese, yogurt, other dairy products, and adult cereals and grains.

To allow a comparison of growth with the WHO and CDC growth curves, $z$ scores were calculated for each growth measure for each infant. The $z$ score is a measure of the distance in SDs from the mean value, calculated as $z=(x-\mu) /{ }^{\prime} \sigma$ ", where " $x$ " denotes the data point of the subject, " $\mu$ " is the mean of the group, and " $\sigma$ " is the SD of the group. For calculation of $z$ scores for the WHO growth standards, the WHO Anthro 2005 software was used. ${ }^{25}$ The WHO growth chart is based on a longitudinal multicenter study of infants in Brazil, Ghana, India, Norway, Oman, and the United States. Infants represented in the WHO growth standards were single-birth, term infants of nonsmoking healthy mothers, with no known health or environmental constraints to growth. The infants were exclusively breastfed for $\geq 4$ months, with complementary foods introduced by 6 months of age, and breastfeeding was continued to $\geq 12$ months of age. ${ }^{26}$ The $z$ scores for the CDC 2000 growth charts were calculated using the EPI INFO software developed by the CDC. ${ }^{27}$ The CDC charts represent the growth of infants to 36 months of age collected in 3 cross-sectional surveys conducted between 1971 and 1994, with some added data because of the limited number of younger-age infants in the initial surveys. The CDC growth charts exclude very low birth weight infants $(<1500 \mathrm{~g})$ but have no inclusion or exclusion criteria related to feeding or environmental variables. ${ }^{28}$ Therefore, our aims in the present study were to illustrate how the growth-curve standard used to assess infant growth influences the interpretation of whether higher weight gain occurs and whether changes in the trajectory of growth are associated with changes in the type of milk feeding or introduction of solid foods.

\section{Statistical Analysis}

This study took advantage of longitudinal measures of growth taken at 8 different ages from birth to 18 months of age in healthy, term gestation infants who were participants in a study addressing the relationship of the maternal $n-3$ fatty acid docosahexaenoic acid status with measures of infant visual, cognitive, and motor skill development. We found no differences in the growth of infants born to women assigned at random to a supplement providing 400 $\mathrm{mg}$ per day of docosahexaenoic acid and those assigned to a placebo from 16 weeks of gestation until delivery of the infant. We, therefore, combined the results for all of the infants for the purpose of the present study. $t$ tests and $X^{2}$ tests were performed to compare the birth weight and family characteristics of infants who were withdrawn by their parents with those of infants who completed the study to 18 months of age. The $z$ scores for weight for age, weight for length, and length for age were plotted against the WHO and CDC growth curves. $z$ scores for BMI were also plotted on the WHO growth curve. BMI curves are not included with the CDC growth curve. Finally, when changes in the patterns of growth from the growth-curve standard were observed, we conducted subanalyses from the growth-curve standard to explore possible associations between shifts in the pattern of growth and whether the infants were breastfed or fed formula, as well as the timing of the introduction of solid foods. 
Dijk, C.E. van, Innis, S.M. Growth-curve standards and the assessment of early excess weight/ gain in infancy. Pediatrics: 2009, 123(1), 102-108

\section{RESULTS}

In the present study, 84 infants were born, 11 infants were withdrawn before they reached 18 months of age, and 73 infants completed the study with no missing data. All of the infants who were withdrawn were withdrawn voluntarily by their parent and not for any known reason associated with the infant's health or feeding. Dropout analyses showed that the 11 infants ( 5 boys and 6 girls) who were withdrawn from the study had a lower birth weight $(P$ $=.02)$ and length $(P=.01)$ than those infants who completed the study; however, all of the infants were withdrawn voluntarily by their parents and not for any known reasons associated with the infant's growth. We could identify no significant differences in family characteristics, including income or ethnicity, between those who withdrew and those who

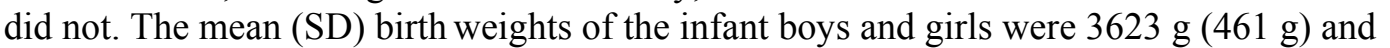
$3294 \mathrm{~g}$ (449) g, respectively (Table 1). Our study population was one mainly of middle class, with only 2 mothers reporting that they had smoked, and no mother reported alcohol or substance abuse during pregnancy. Of the infants in the present study, $60 \%$ were white, and $29 \%$ were of Asian background, reflecting the population characteristics in city of Vancouver. $^{29}$

\section{[TABLE 1]}

At 1 month of age, $85 \%$ of all of the infants in the present study were exclusively breastfed, although $76 \%$ of the infants in our study were fed with an infant formula during infancy. Only 17 infants were never fed with an infant formula. The mean age of introduction of infant formula, excluding those infants who were never fed formula, was 5.9 months of age. The age of introduction of complementary foods followed current infant feeding guidelines for introduction of iron-fortified infant cereals, vegetables, fruits, and whole cows' milk. ${ }^{30}$ Thus, in the present study, every infant was fed with infant cereals, vegetables, and fruits, with a mean age of introduction of 5.7,6.5, and 6.7 months of age, respectively. Of the 73 infants followed to 18 months of age, 2 were never fed red meat, 1 was never fed poultry, and 6 were never fed fish. The mean age of introduction of red meat, poultry, and fish for the infants fed these foods was $9.5,8.8$, and 10.7 months, respectively. The mean age of introduction of bottle feeds with cows' milk was 12.4 months, and 6 infants were never bottle fed with cows' milk. We found no significant difference in the age introduction of solid foods or feeding with infant formula between the infant girls and boys (data not shown).

\section{Comparison of WHO Growth Standard and CDC 2000 Growth Charts}

The pattern of infant growth from birth to 18 months compared with the WHO standard and CDC charts is illustrated in Fig 1. We draw attention to the comparison of infant weight for age using the WHO growth standard and the CDC growth chart (Fig 1B). Here we show that, although the weight for age of the infants in our study crossed the CDC growth chart at $\sim 6$ months of age, with a downward trend to lower weight for age in our Canadian infants when compared with US infants, weight for age increased on the WHO growth curves. When assessing weight for length (Fig 1C), the infants in our study were initially below the growthcurve standards explained by a higher length at birth (Fig 1A) but grew following both the $\mathrm{CDC}$ and WHO growth curves from $\sim 2$ to 6 months of age, after which the trend to higher weight for length became apparent in the WHO growth standards but not the CDC growth curve. When plotted on the WHO growth standard for BMI, the shift in growth pattern from $\sim 6$ month of age among our infants was clearly illustrated (Fig 1D), which, from the lengthfor-age and weight-for-age curves (Fig 1A and 1B), was explained by an excess weight gain relative to length gains.

\section{[FIGURE 1]}

In Fig 2 we illustrated the weight-for-age $z$ scores for the infant boys and girls. Again, the same pattern was demonstrated in which infants in our study showed decreased gains in weight for age after 6 months of age, when assessed using the CDC growth curves, but an 
Dijk, C.E. van, Innis, S.M. Growth-curve standards and the assessment of early excess weight/ gain in infancy. Pediatrics: 2009, 123(1), 102-108

increased in growth rates when assessed using the WHO growth standards. The concern raised was both potential misinterpretation of lower weight-for-age gains and failure to identify the onset of the early upward trend in weight gains when infant growth was assessed using the $\mathrm{CDC}$ growth charts rather than the WHO growth standard. The different weight for age between the 2 growth charts was $\sim 0.5$ SDs for both infant girls and boys after 12 months of age. The question of whether tracking infant growth using the CDC curves could foster early excess weights among young infants was self-evident.

\section{[FIGURE 2]}

An additional important question was whether the shift in growth pattern occurring at $\sim 6$ months of age was associated with a change in infant feeding. To explore this question, we considered the growth of the infants who were breastfed without any bottle feeding to $\geq 9$ months of age $(\mathrm{n}=25)$ or bottle fed with breastfeeding discontinued before 6 months of age $(\mathrm{n}=28)$, thus not including those infants in whom feeding was mixed over the timing of the shift in growth pattern. It was notable that, although the number of infants who were breastfed to $\geq 9$ months-of-age was low, the growth of these infants did closely follow the WHO growth standards for both boys and girls (Fig 3). On the other hand, the infants who were fed with formula by 6 months of age had a different pattern of growth, with an inflection in their weight-for-age gains, particularly evident in the boys, by $\sim 6$ months of age. Our results again showed a difference of $\sim 0.5 \mathrm{SDs}$ in weight for age between the infants who were breastfed to 9 months of age and those who were bottle fed with formula by 6 months of age. It is important to note the shift in the weight-for-age growth pattern, which occurred between 6 and 9 months of age, over the time during which solid foods, including infant cereals, vegetables, and fruit, were introduced. Thus, our results did not infer that infant formula itself leads to excess weight-for-age gains in infants but that the feeding dynamics, including the caregiver, infant, and potentially the nature of the foods and how they are fed alter growth when compared with infants who are breastfed. Within this context, however, our results showed no evidence of difference in the types of foods or ages at which different foods were introduced to the infants in our study (data not shown).

\section{[FIGURE 3]}

\section{DISCUSSION}

In the present study we took advantage of longitudinal measures of growth in healthy termgestation infants to address how the choice of growth chart influences the interpretation of weight gain in infancy. We showed important differences in the interpretation of weight gains when using the WHO growth standards compared with the CDC growth chart, which are especially important in assessing gains in weight for age. Compared with the WHO growth standards, the Canadian infants in our study showed an increase in the rate of weight gain beginning between 6 and 9 months of age. The increased rate of weight gain occurred concurrently with changes in infant feeding, with our results suggesting that a change from breastfeeding to bottle feeding was associated with an upward shift in the rate of weight gain. Notably, although the number of infants in our study who were not bottle fed before 9 months of age was low $(n=25)$, the growth of these Canadian breastfed infants followed the WHO growth standard, but when compared with the CDC growth charts, these infants showed an apparent decline in weight for age beginning at $\sim 6$ months of age.

De Onis et al, ${ }^{23}$ by comparing the CDC growth curves and WHO growth standards, recently provided a clear demonstration that children in the United States are heavier and somewhat shorter than the infants represented in the WHO growth standard. The present study with Canadian infants confirms and extends the work of de Onis et $\mathrm{al}^{23}$ and shows the implications of choice of which of these 2 growth-curve standards to use to assess growth, with infants in 
our study appearing to show an upward trend in weight gain after 6 months of age based on the WHO weight-for-age growth curve but a downward trend in weight gain based on the $\mathrm{CDC}$ growth chart. Although the CDC growth curve is based on cross-sectional data on infants collected in 3 surveys in the United States, the recently developed WHO growth standards represent infants exclusively breastfed to 6 months of age, with the introduction of solid foods by 6 months of age. Current infant feeding guidelines in Canada are consistent with the WHO study population and include a recommendation to exclusively breastfeed to 6 months of age, with introduction of an iron-fortified infant cereal as the first complementary food. ${ }^{30}$ The infant girls and boys in our study population who met these feeding criteria grew following the WHO weight-for-age growth standard, confirming that this standard is the standard of choice for assessing early growth.

Several studies have highlighted differences in the rate of growth, particularly in the second 6 months after birth between breastfed and bottle-fed infants, with bottle-fed infants gaining more weight than breastfed infants. ${ }^{31,32}$ Suggested reasons for the difference in growth between breastfed and bottle-fed infants include differences in nutrient intake and responses to hunger and satiation. ${ }^{32-34}$ Although our study was limited to descriptive analyses, the results of the present study also provide demonstration of a difference in weight for age between breastfed and formula-fed infants, with a difference of $\sim 0.5$ SDs on the weight-forage curves for the boys on both the WHO growth standard and CDC growth chart at 18 months of age. Many factors in addition to effects of components in human milk in influencing energy metabolism or appetite, including possible effects of the nature of the foods other than breast milk offered to the infants, as well as differences in feeding practices, could contribute to differences in growth between breastfed and bottle-fed infants. However, in the present study, we could identify no evidence of any differences in the timing of introduction of solid foods between infants who were bottle fed before 6 months and infants who were breastfed for $\geq 9$ months, although bottle feeding and the introduction of solid foods occurred concurrently with increased rate of weight gains among bottle-fed infants, as also shown in previous studies. ${ }^{35}$ Our study was not designed to collect quantitative information on formula intakes or on complementary food intakes, nor can we address reporting errors or bias in the mother's report of infant feeding practices. Regardless, our work shows that early deviations in growth, with an upward trend in weight gains, do occur in young infants and are related to the way in which infants are fed. These results are important in light of the findings of several large studies that show that breastfed infants have a lower risk of later overweight than bottle-fed infants, ${ }^{36-38}$ and clearly infant feeding practices are modifiable risk factors.

\section{CONCLUSIONS}

In this report we have provided illustration that the choice of growth-curve standard is of central importance in assessing and identifying the onset of excess body weight gain in young infants. We did not extend our results to interpret the prevalence of excess weight gain in the community or in other populations. We showed that interpretation of appropriate rates of weight-for-age gain and the impact of diet and environment will differ with the growth standard used. We now suggest that identification of the prevalence and age of onset of early excess weight gains among our infant populations and the determinants of risk will be best achieved by population-based studies using the WHO growth standard. The prevalence of overweight and obesity is increasing in children and is occurring at younger ages. ${ }^{1-6} \mathrm{We}$ showed that breastfed infants in Canada follow the WHO growth standard, regardless of ageappropriate introduction of solid foods. Our results suggest that bottle feeding and the introduction of solid food, as shown by others, ${ }^{35}$ are associated with an increase in the rate of body weight gain between 6 and 9 months of age. We suggest that a more stringent approach using the WHO growth standard is needed to assess early infant growth, with the aim of developing effective intervention strategies for avoiding early excess weight gain. 
Dijk, C.E. van, Innis, S.M. Growth-curve standards and the assessment of early excess weight gain in infancy. Pediatrics: 2009, 123(1), 102-108

\section{ACKNOWLEDGMENTS}

These studies were funded by a research grant from the Canadian Institutes for Health Research.

We gratefully acknowledge Ruth Milner for statistical advice and Shalu Duggal and the clinical nutrition research team for their work in the measurements of infant growth and dietary assessments.

\section{FOOTNOTES}

\section{What's Known on This Subject}

Increasing overweight and obesity are growing problems among children worldwide. Prevention requires understanding of when excess weight gain begins. The growth-curve standard used to assess weight gain is of central importance to identifying when early excess weight gain begins.

\section{What This Study Adds}

This study illustrates how the growth standard influences the interpretation of growth. We show that weight gains of Canadian breastfed infants follow the WHO standard but fall below the CDC standard; increased weight gain with bottle feeding at 6 months of age is shown with the WHO standard.

\section{REFERENCES}

- Dehghan M, Akhtar-Danesh N, Merchant AT. Childhood obesity, prevalence and prevention. J Nutr. 2005;2:4:24

- Fry J, Finley W. The prevalence and costs of obesity in the EU. Proc Nutr Soc. 2005;64 (3):359-362

- Tjepkema M. Adult obesity. Health Rep. 2006;17:9-25

- Shield M. Overweight and obesity among children and youth. Health Rep. 2006;17 (3):27 -42

- Kosti RI, Panagiotakos DB. The epidemic of obesity in children and adolescents in the world. Cent Eur J Public Health. 2006;14 (4):151 -159

- Wabitsch M. Overweight and obesity in European children: definition and diagnostic procedures, risk factors and consequences for later health outcome. Eur J Pediatr. 2000;159 (suppl 1):S8 -S13

- Burke V. Obesity in childhood and cardiovascular risk. Clin Exp Pharmacol Physiol. 2006;33 (9):831-837

- Kaufman FR. Type 2 diabetes mellitus in children and youth: a new epidemic. J Pediatr Endocrinol Metab. 2006;15 (suppl 2):737 -744

- Weiss R, Dziura J, Burgert TS, et al. Obesity and the metabolic syndrome in children and adolescents. N Engl J Med. 2004;350 (23):2362 -2374

- Ito H, Nakasuga $\mathrm{K}$, Ohshima A, et al. Excess accumulation of body fat is related to dyslipidemia in normal-weight subjects. Int J Obes Relat Metab Disord. 2004;28 (2):242 -247

- Visser M, Bouter LM, McQuillan GM, Wener MH, Harris TB. Elevated C-reactive protein levels in overweight and obese adults. JAMA. 1999;282 (22):2131 -2135

- Khaodhiar L, Ling PR, Blackburn GL, Bistrian BR. Serum levels of interleukin-6 and C-reactive protein correlate with body mass index across the broad range of obesity. J Parenter Enteral Nutr. 2004;28 (6):410 -415

- Cruz ML, Shaibi GQ, Weigensberg MJ, Spruijt-Metz D, Ball GD, Goran MI. Pediatric obesity and insulin resistance: chronic disease risk and implications for treatment an prevention beyond body weight modification. Annu Rev Nutr. 2005;25:435-468

- Sbarbati A, Osculati F, Silvagni D, et al. Obesity and inflammation: evidence for an elementary lesion. Pediatrics. 2006;117 (1):220 -223

- Chen H. Cellular inflammatory responses: novel insights for obesity and insulin resistance. Pharmacol Res. 2006;53 (6):469-477 
Dijk, C.E. van, Innis, S.M. Growth-curve standards and the assessment of early excess weight gain in infancy. Pediatrics: 2009, 123(1), 102-108

- Pausova Z. From big fat cells to high blood pressure: a pathway to obesityassociated hypertension. Curr Opin Nephrol Hypertens. 2006;15 (2):173 -178[ISI]

- Stettler N, Zemel BS, Kumanyika S, Stallings VA. Infant weight gain and childhood overweight status in a multicenter, cohort study. Pediatrics. 2002;109 (2):194-199

- Vogels N, Posthumus DL, Mariman EC, et al. Determinants of overweight in a cohort of Dutch children. Am J Clin Nutr. 2006;84 (4):717 -724

- Magarey AM, Daniels LA, Boulton TJ, Cockington RA. Predicting obesity in early adulthood from childhood and parental obesity. Int J Obes Relat Metab Disord. 2003;27 (4):505 -513

- Williams S. Overweight at age 21: the association with body mass index in childhood and adolescence and parents' body mass index. A cohort study of New Zealanders born in 1972-1973. Int J Obes Relat Metab Disord. 2001;25 (2):158 -163

- Lake A, Townshend T. Obesogenic environments: exploring the built and food environments. J R Soc Health. 2006;126 (6):262 -267

- Marti A, Moreno-Aliaga MJ, Hebebrand J, Martinez JA. Genes, lifestyles and obesity. Int J Obes Relat Metab Disord. 2004;28 (suppl 3):S29 -S36

- de Onis M, Garza C, Onyango AW, Borghi E. Comparison of the WHO Child Growth Standard and the CDC 2000 Growth Charts. J Nutr. 2007;137 (1):144-148

- Innis SM, Gilley J, Werker J. Are human-milk long-chain polyunsaturated fatty acids related to visual and neural development in breast-fed infants? J Pediatrics. 2001;139 (4):532 -537

- World Health Organization. Child growth standards. WHO Anthro 2005 software and macros. World Health Organization Web site. Available at: www.who.int/childgrowth/software/en. Accessed April 19, 2007

- Garza C, de Onis M. Rationale for developing a new international growth reference. Food Nutr Bull. 2004;25 (1 suppl):S1 -S14

- Dean A, Arner T, Sangam S, et al. Epi Info 2000, A Database and Statistics Program for Public Health Professionals for Use on Windows 95, 98 NT and 2000 Computers. Atlanta, GA: Centers for Disease Control and Prevention; 2000

- Kuczmarski RJ, Ogden CL, Grummer-Strawn LM, et al. CDC growth charts: United States. Adv Data. 2000;(314):1-27

- Innis SM, Palaty J, Vaghri Z, Lockitch G. Increased levels of mercury associated with high fish intakes among children from Vancouver. Can J Pediatr. 2006;148 (6): $759-763$

- Canadian Paediatric Society, Dietitians of Canada and Health Canada. Nutrition for Healthy Term Infants. Ottawa, Ontario, Canada: Minister of Public Works and Government Services; 2005

- Kramer MS, Guo T, Platt RW, et al. Feeding effects on growth during infancy. J Pediatr. 2004;145 (5):600 -605

- Butte NF, Wong WW, Hopkinson JM, Smith EO, Ellis KJ. Infant feeding mode affects early growth and body composition. Pediatrics. 2000;106 (6):1355 -1366

- Heinig MJ, Nommsen LA, Peerson JM, Lonnerdal B, Dewey KG. Energy and protein intakes of breast-fed and formula-fed infants during the first year of life and their association with growth velocity: the DARLING Study. Am J Clin Nutr. 1993;58 (2):152-161

- Fisher JO, Birch LL, Smiciklas-Wright H, Picciano MF. Breast-feeding through the first year predicts maternal control in feeding and subsequent toddler energy intakes. J Am Diet Assoc. 2000;100 (6):641 -646

- Baker JL, Michaelsen KF, Rasmussen KM, Sørensen TIA. Maternal prepregnant body mass index, duration of breastfeeding, and timing of complementary food introduction are associated with infant weight gain. Am J Clin Nutr. 2004;80 (6):1579 $-1588$

- $\quad$ Arenz S, Ruckerl R, Koletzko B, von Kries R. Breast-feeding and childhood obesitya systematic review. Int J Obes Relat Metab Disord. 2004;28 (10):1247 -1256

- Michels KB, Willett WC, Graubard BI, et al. A longitudinal study of infant feeding and obesity throughout life course. Int J Obes (Lond). 2007;31 (7):1078 -1085 
Dijk, C.E. van, Innis, S.M. Growth-curve standards and the assessment of early excess weight gain in infancy. Pediatrics: 2009, 123(1), 102-108

- Shields L, O'Callaghan M, Williams GM, Najman JM, Bor W. Breastfeeding and obesity at 14 years: a cohort study. J Paediatr Child Health. 2006;42 (5):289 -296

TABLES

TABLE 1 Population Characteristics

Placebo

\section{Characteristic}

No. of infants

Maternal

White/nonwhite, $n / n$

Maternal age, mean \pm SD, y

Smoking, $n$

Infant

Birth weight, mean $\pm \mathrm{SD}, \mathrm{g}$

Birth length, mean $\pm \mathrm{SD}$, cm

Birth head circumference, mean $\pm \mathrm{SD}$, cm

Weight, mean $\pm \mathrm{SD}, \mathrm{g}, 18$ mo

Length, mean $\pm \mathrm{SD}$, cm, 18 mo

Head circumference, mean \pm $\mathrm{SD}, \mathrm{cm}, 18 \mathrm{mo}$
Boys

Girls

17

19

$16 / 3$

$13 / 4$

$11 / 5$

$12 / 8$

$33.9 \pm$

3.6

$34.8 \pm$

3.4

$31.6 \pm$

5.2

2

0

1

$33.4 \pm 4.0$

$3602 \pm$

500

$3509 \pm$

494

$3649 \pm$

425

$3453 \pm$

$52.6 \pm$

$52.7 \pm$

$52.2 \pm$

3.0

2.1

2.0

$35.2 \pm$

$34.8 \pm$

$34.9 \pm$

1.2

1.1

1.5

$\begin{array}{llll}11306 \pm & 10508 \pm & 11651 \pm & 10302 \pm\end{array}$ 1354

1212

1397

$1101^{\mathrm{a}}$

$81.9 \pm$

$80.8 \pm$

$82.9 \pm$

$80.7 \pm$

3.2

3.2

2.7

$3.1^{\mathrm{a}}$

$49.2 \pm$

$47.2 \pm$

$48.8 \pm$

$1.2^{\mathrm{b}}$

1.4

$47.1 \pm$

0.9 $1.4^{\mathrm{a}}$

${ }^{\mathrm{a}} \mathrm{P}<.05$ for girls compared with boys, by group. 
Dijk, C.E. van, Innis, S.M. Growth-curve standards and the assessment of early excess weight/ gain in infancy. Pediatrics: 2009, 123(1), 102-108

FIGURE 1 Mean $z$ scores relative to the WHO standard and the CDC chart. A, Length for weight for age; B, weight for age; C, weight for length; D, BMI for age. Shown is a comparison of length-for-age, weight-for-age, and weight-for-length $z$ scores for infants assessed longitudinally from birth to 18 months of age and plotted on the WHO standard and CDC 2000 charts. The change in BMI with age plotted on the WHO standard is also shown.

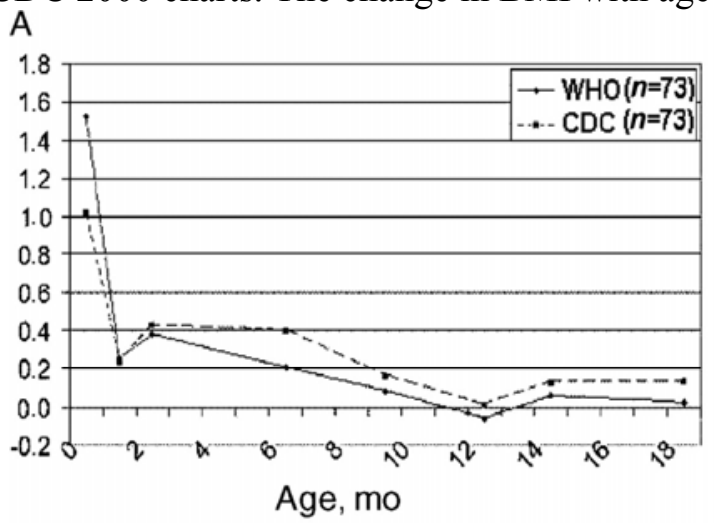
$B$

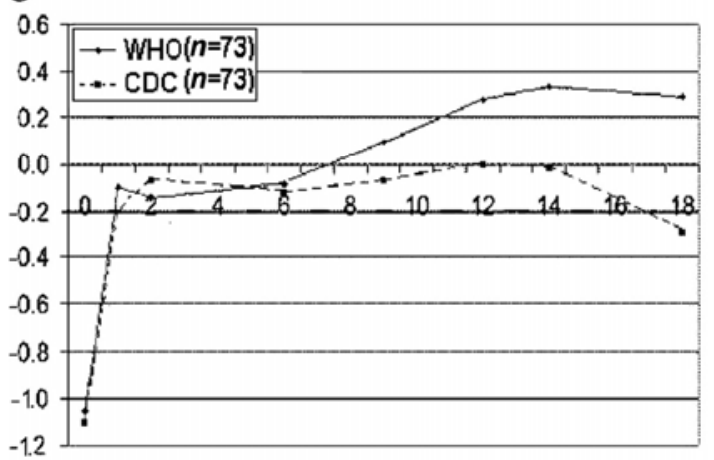

Age, mo
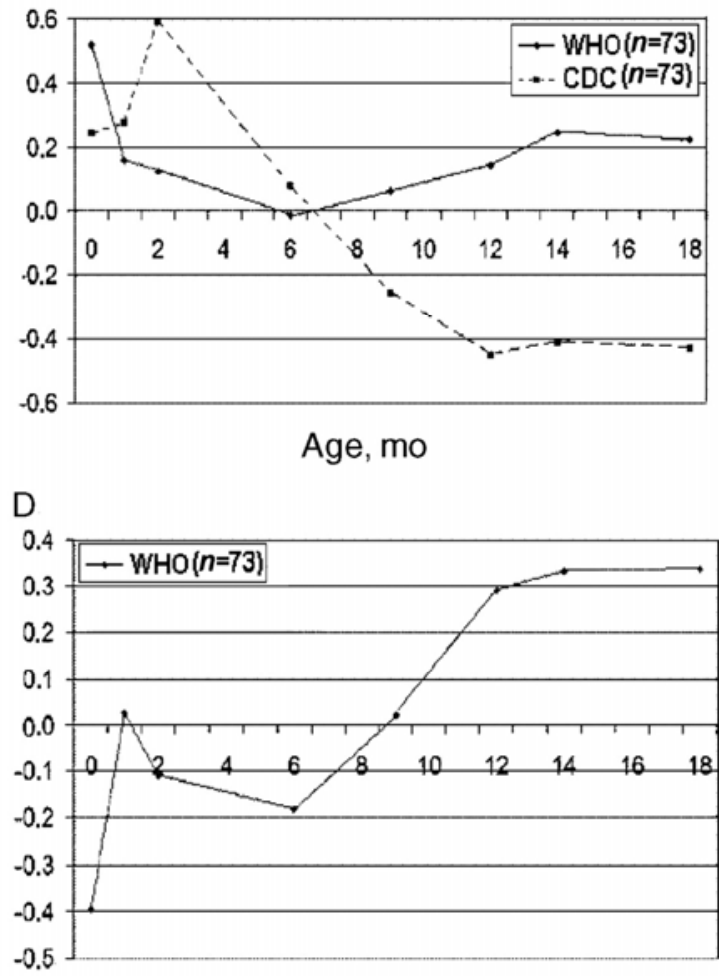

Age, mo

FIGURE 2 Comparison between boys and girls of weight-for-age $z$ scores relative to the WHO standard and the CDC 2000 charts.

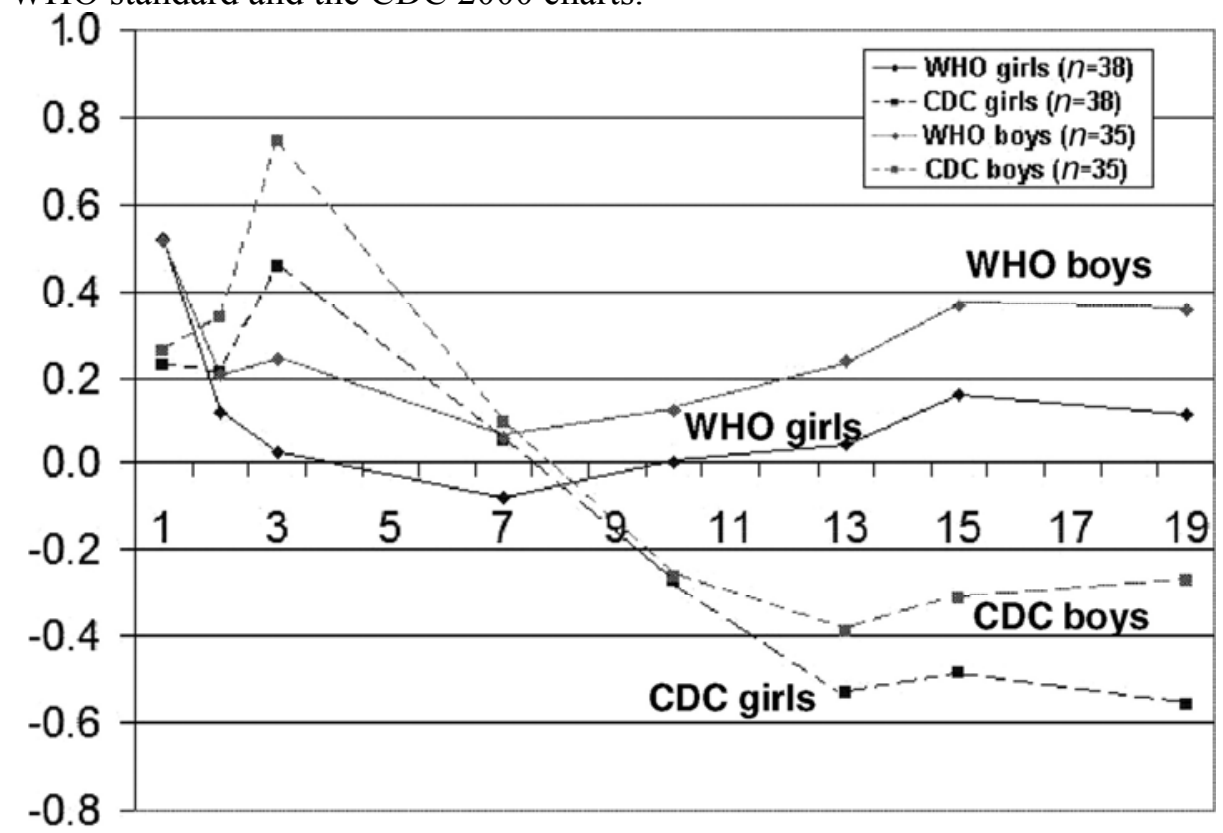

Age, mo 
Dijk, C.E. van, Innis, S.M. Growth-curve standards and the assessment of early excess weight/ gain in infancy. Pediatrics: 2009, 123(1), 102-108

FIGURE 3 Comparison of mean weight-for-age $z$ scores relative to the WHO standard and the CDC 2000 charts between breastfed and bottle-fed infants in boys (left) and girls (right).

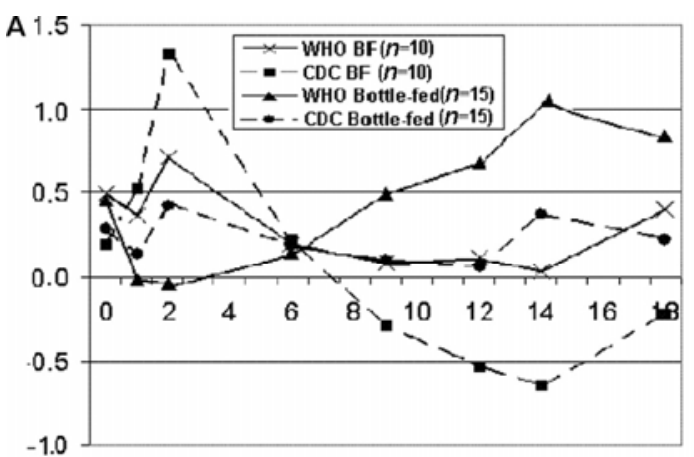

Age, mo

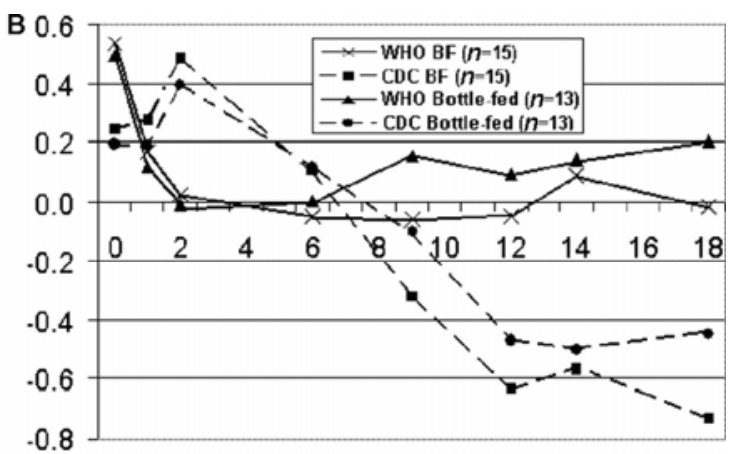

Age, mo 